\title{
The BaBar Superconducting Coil: Design, Construction and Test
}

R. A. Bell, M. Berndt, W. Burgess, W. Craddock, O. Dormicchi, P. Fabbricatore, S. Farinon, L. Keller, $P$. Moreschi, R. Musenich, T. G. O'Conner, R. Penco, C. Priano, S. Shen, $P$. Valente

This article was submitted to $15^{\text {th }}$ International Conference on Magnet Technology, Beijing, China,
October 22-24, 1997

U.S. Department of Energy

Lawrence

Livermore

National

Laboratory

January 26, 2001 


\section{DISCLAIMER}

This document was prepared as an account of work sponsored by an agency of the United States Government. Neither the United States Government nor the University of California nor any of their employees, makes any warranty, express or implied, or assumes any legal liability or responsibility for the accuracy, completeness, or usefulness of any information, apparatus, product, or process disclosed, or represents that its use would not infringe privately owned rights. Reference herein to any specific commercial product, process, or service by trade name, trademark, manufacturer, or otherwise, does not necessarily constitute or imply its endorsement, recommendation, or favoring by the United States Government or the University of California. The views and opinions of authors expressed herein do not necessarily state or reflect those of the United States Government or the University of California, and shall not be used for advertising or product endorsement purposes.

This is a preprint of a paper intended for publication in a journal or proceedings. Since changes may be made before publication, this preprint is made available with the understanding that it will not be cited or reproduced without the permission of the author.

This work was performed under the auspices of the United States Department of Energy by the University of California, Lawrence Livermore National Laboratory under contract No. W-7405-Eng-48.

This report has been reproduced directly from the best available copy.

Available electronically at http://www.doc.gov/bridge

Available for a processing fee to U.S. Department of Energy

And its contractors in paper from

U.S. Department of Energy

Office of Scientific and Technical Information

P.O. Box 62

Oak Ridge, TN 37831-0062

Telephone: (865) 576-8401

Facsimile: (865) 576-5728

E-mail: reports@adonis.osti.gov

Available for the sale to the public from

U.S. Department of Commerce

National Technical Information Service

5285 Port Royal Road

Springfield, VA 22161

Telephone: (800) 553-6847

Facsimile: (703) 605-6900

E-mail: orders@ntis.fedworld.gov

Online ordering: http://www.ntis.gov /ordering.htm

OR

Lawrence Livermore National Laboratory Technical Information Department's Digital Library

http://www.Ilnl.gov/tid/Library.html 
The BaBar superconducting coil: design, construction and test

R.A.Bell ${ }^{\mathrm{a}}$, M.Berndt ${ }^{\mathrm{a}}$, W.Burgess ${ }^{\mathrm{a}}$, W.Craddock ${ }^{\mathrm{a}}$, O. Dormicchi ${ }^{\mathrm{b}}$, P.Fabbricatore ${ }^{c}$, S.Farinon ${ }^{c}$, L.Keller, P.Moreschi ${ }^{b}$, R.Musenich ${ }^{c}$, T.G. O'Connor ${ }^{d}$, R.Penco ${ }^{b}$, C.Priano ${ }^{c}$, S. Shen ${ }^{d}$, , P.Valente

${ }^{\text {a}}$ Stanford Linear Accelerator Center (SLAC), USA

${ }^{\mathrm{b}}$ Ansaldo Energia

via N.Lorenzi , 8 Genova, Italy

'Istituto Nazionale di Fisica Nucleare- Genova

via Dodecaneso 33, 16146 Genova, Italy

'Lawrence Livermore National Laboratory, USA

The BABAR Detector, located in the PEP-II B-Factory at the Stanford Linear Accelerator Center, includes a large 1.5 Tesla superconducting solenoid, $2.8 \mathrm{~m}$ bore and length $3.7 \mathrm{~m}$. The two layer solenoid is wound with an aluminum stabilized conductor which is graded axially to produce a $+/-3 \%$ field uniformity in the tracking region. This paper summarizes the 3 year design, fabrication and testing program of the superconducting solenoid. The work was carried out by an international collaboration between INFN, LLNL and SLAC . The coil was constructed by Ansaldo Energia. Critical current measurements of the superconducting strand, cable and conductor, cool-down, operation with the thermo-siphon cooling, fast and slow discharges, and magnetic forces are discussed in detail.

\section{INTRODUCTION}

The magnet for the BaBar experiment at PEP-II in SLAC [1] is a thin superconducting solenoid within a hexagonal flux return. As shown in Fig. 1 the solenoid is cylinder just inside the flux return.

The Letter of Intent for the Study of CP Violation and Heavy Flavor Physics at PEPII was presented by BaBar Collaboration on June 1994. At that time, the studies performed on detector resolution for decay $\mathrm{B}^{0} \longrightarrow \pi^{+} \pi^{-}$showed that, to achieve a good momentum resolution ( $<25 \mathrm{MeV} / \mathrm{c}^{2}$ ) in the Drift Chamber without increasing the tracking volume, $1.5 \mathrm{~T}$ magnetic field was needed. In addition the limited space allowed to the coil led to the choice of a superconducting magnet. The magnetic field was required to be uniform in the tracker volume. Combined radius of vertex detector, tracker, particle identification system, electromagnetic calorimeter and suitable clearances led to $3 \mathrm{~m}$ inner bore. The tracking of the muons and $\mathrm{K}_{\mathrm{L}}^{0}$ 's detection asked for a segmented iron flux return. The design was based on criteria developed and tested over the last 15 years with detector magnets employing aluminum-stabilized thin solenoids [2]. The double layer coil is internally wound on a $35 \mathrm{~mm}$ thick 5083 aluminum support mandrel. Cooling pipes welded to the outside diameter of the support mandrel form part of the thermo-siphon system. Electrical insulation consists of dry wrap fiberglass cloth and epoxy vacuum impregnation.

The final coil parameter are shown in Table 1.

The Technical Design Report was issued on March 1995 and reviewed the same month at SLAC. 
Table 1

Main characteristics of BaBar solenoid (as built)

\begin{tabular}{ll}
\hline Central Induction & $1.5 \mathrm{~T}$ \\
Conductor peak field & $2.3 \mathrm{~T}$ \\
Winding structure & 2 layers \\
& $\begin{array}{l}\text { graded current } \\
\text { density }\end{array}$ \\
& \\
Uniformity in the tracking $\pm 3 \%$ \\
region \\
Winding axial length & $3512 \mathrm{~mm}$ at R.T \\
Winding mean radius & $1530 \mathrm{~mm}$ at $R . T$. \\
Operating current & $4596 \mathrm{~A}$ \\
Inductance & $2.57 \mathrm{H}$ \\
Stored Energy & $27 \mathrm{MJ}$ \\
Total turns & 1067 \\
Total length of conductor & $10300 \mathrm{~m}$
\end{tabular}

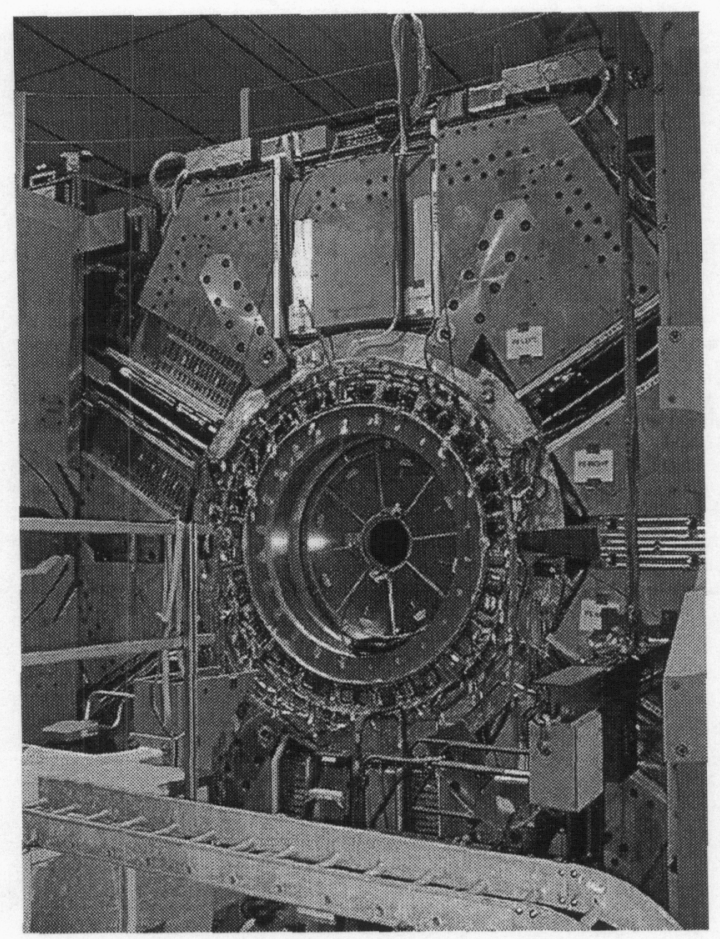

Figure 1. View of BABAR solenoid in the hexagonal (photo taken on September 1998)
The magnetic system was identified to be composed by:

- The solenoid

- The laminated barrel and end caps flux return, composed each by 20 steel plates of different thickness (after modified to 17 plates). A gap of $150 \mathrm{~mm}$ between barrel and end caps allowed a path for detector wiring.

- The Q2 shield in the forward end door

- An iron shield in the backward end door.

The chosen option for the Particle Identification (DIRC) and the $\mathrm{Q} 2$ shielding led to a strong asymmetry in the iron flux return and then to axial offset force of about 45 ton (after optimization of the end plugs geometry). The constraints coming from the detector's needs led to choose a coil similar to $\mathrm{CDF}$ coil, involving soft $\mathrm{Al}$ stabilised conductor ( A superconducting cable embedded in a ultrapure Aluminium matrix). The hoop strength is provided by an aluminium alloy cylinder

\section{CONDUCTOR}

The conductor (shown in fig.2) is composed of a superconducting Rutherford type cable embedded in a pure aluminum matrix through a co-extrusion process, which ensures good bonding between the aluminum and the superconductor. In order to have a field homogeneity of $+/-3 \%$ in the large volume specified by the $\mathrm{BaBar}$ experiment, the current density in the winding is graded: lower in the central region and higher at the ends. The gradation is obtained by using conductor of two different thickness: $8.4 \mathrm{~mm}$ for the central region and $5 \mathrm{~mm}$ for the ends. Both $20 \mathrm{~mm}$ wide conductors are composed of a 16 strand Rutherford cable stabilized by pure aluminum. Table 2 describes the strands, the Rutherford cable and the final conductor characteristics. The conductors were supplied by Europa Metalli (Fornaci di Barga -Italy). The co-extrusion processes were carried out at ALCATEL SWISS CABLE under assistance of ETH Zurich 


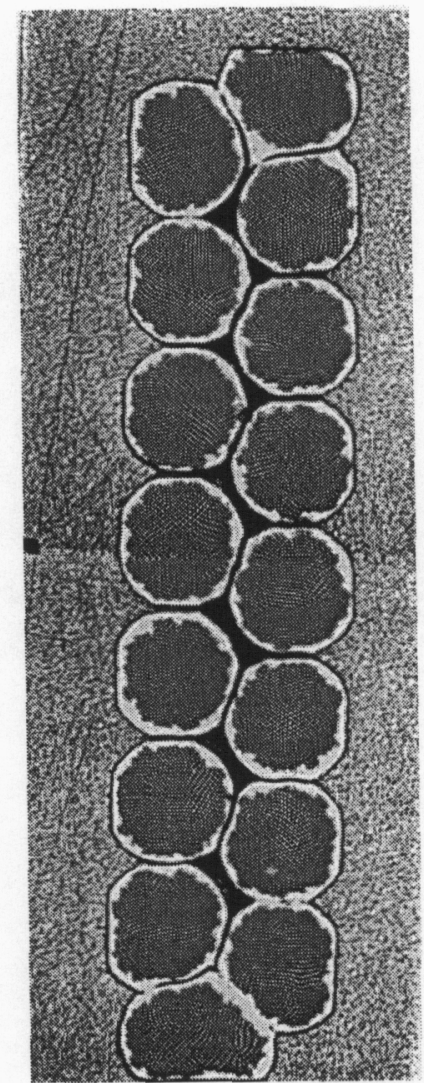

Figure 2. Cross section of the conductor

Critical current measurements were carried out on the Rutherford cables which were extracted from the pure aluminum matrix by chemical etching. The samples were arranged with the field normal to the wide face in order to reproduce the same field conditions experienced by the conductor inside the BaBar coil.

The short samples were measured in the facility MA.RI.S.A., using the transformer method [3]. For each short sample, critical current measurements were performed at different magnetic fields, as shown in Fig. 3. The critical field at $2.5 \mathrm{~T}$ was extrapolated from Fig. 2. The critical current for all lengths is greater then the specified value: $\mathrm{Ic}(\mathrm{B}=2.5 \mathrm{~T} ; \mathrm{T}=4.2 \mathrm{~K})=12680 \mathrm{~A}$.

In sample \#3 the superconducting to normal transition was not observed, because the sample quenched before a significant voltage was measured. This was attributed to poor soldering of the sample within its holder. For this sample only, the quench current at different applied magnetic fields was measured.

The peak field in the BaBar coil preliminary design, a single layer winding, was $\mathrm{B}_{\text {peak }}=2.5 \mathrm{~T}$. At this field the critical temperature for $\mathrm{NbTi}$ is $\mathrm{T}_{\mathrm{C}}=8.27 \mathrm{~K}$. The current sharing temperature for this single layer design is $6.79 \mathrm{~K}$.

During the engineering design phase the coil configuration was modified from a single layer to a double layer design to increase the stability margin. This led to a reduction in the peak field of the thin conductor from 2.5 $\mathrm{T}$ to $2.3 \mathrm{~T}$.

Considering the effective packing factor of the constructed coil, the nominal current was found to be $I n=4605 \mathrm{~A}$. Since the field is higher in the inner layer, making this the more critical layer, the conductor margins were re-computed taking into account modifications to the peak field, critical current, and nominal current for these three sectors. The highest $I_{n}$ over $I_{c}$ ratio for the thick conductor was, $I_{n} / I_{c}=0.33$. The lowest current sharing temperature is the forward thin conductor, $\mathrm{T}_{\mathrm{g}}=7.28 \mathrm{~K}$. As a result of changing to a 2-layer design the coil has more temperature margin than the original single layer coil

A parameter of interest is the enthalpy variation from $4.5 \mathrm{~K}$ to $7.28 \mathrm{~K}$ :

$$
E_{u . v .}=\int_{4.5}^{7.28} C p(T) \delta d T
$$

where $\mathrm{Cp}(\mathrm{T})$ is the specific heat (in $\mathrm{J} / \mathrm{Kg}$ ) and $\delta$ the density. By averaging the thermal properties among the four components of the winding, aluminum, copper, $\mathrm{NbTi}$ and fiberglass epoxy, we find $\mathrm{E}_{\text {u.v. }}=3635 \mathrm{~J} / \mathrm{m}^{3}$. 
Table 2

Summary of specification for strands, Rutherford and full conductor

\begin{tabular}{|c|c|c|}
\hline Component & Characteristic & Value \\
\hline \multirow[t]{4}{*}{ Strand } & $\mathrm{NbTi}$ & $\begin{array}{c}\mathrm{Nb} 46.5+1-1.5 \\
\text { wt } \% \mathrm{Ti}\end{array}$ \\
\hline & Filament size & $<40 \mu \mathrm{m}$ \\
\hline & $\mathrm{Cu} / \mathrm{NbTi}$ ratio & $>1.1$ \\
\hline & Wire diameter & $0.8 \mathrm{~mm} \pm 0.005$ \\
\hline \multirow[t]{3}{*}{ Rutherford } & $\begin{array}{l}\text { Transposition } \\
\text { pitch }\end{array}$ & $<90 \mathrm{~mm}$ \\
\hline & No. of strands & 16 \\
\hline & Final size & $1.4 \times 6.4 \mathrm{~mm} 2$ \\
\hline \multirow[t]{10}{*}{ Conductor } & Al-RRR & $>1000$ \\
\hline & Dim. (mm): & \\
\hline & Thin conductor & $(4.93 \times 20) \pm 0.02$ \\
\hline & Thick conductor & $(8.49 \times 20) \pm 0.02$ \\
\hline & $\begin{array}{l}\text { Rutherford-Al } \\
\text { bonding }\end{array}$ & $>20 \mathrm{MPa}$ \\
\hline & $\mathrm{A} / \mathrm{Cu} / \mathrm{Nb} \mathrm{Ti}^{-}$ & \\
\hline & Thin conductor & $23.5: 1.1: 1$ \\
\hline & Thick conductor & $42.4: 1.1: 1$ \\
\hline & $\begin{array}{l}\text { Edge curvature } \\
\text { radius }\end{array}$ & $>0.2 \mathrm{~mm}$ \\
\hline & $\begin{array}{l}\text { Critical current } \\
@ \mathrm{~T}=4.2 \mathrm{~K} \mathrm{~B}=2.5 \mathrm{~T}\end{array}$ & $12680 \mathrm{~A}$ \\
\hline
\end{tabular}

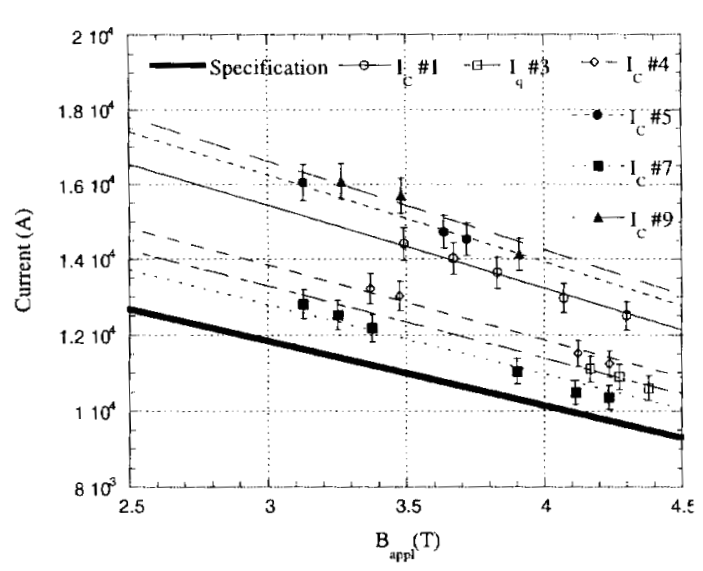

Figure 3 Critical current and quench currents vs. applied field [where applied field is external field plus the sample self field $\left.\left(\mathrm{B}_{\mathrm{sf}}=0.68 \mathrm{Gauss} / \mathrm{A}\right)\right]$ performed on the six samples. The thick solid line represents the specification.
This enthalpy margin can be re-written in a more convenient way as energy per unit conductor length, resulting $\mathrm{E}_{\mathrm{u} .1 .}=0.36 \mathrm{~J} / \mathrm{m}$ for thin conductor and $E_{u .1}=0.65 \mathrm{~J} / \mathrm{m}$ for thick conductor. As comparison, ALEPH and CDF, two well known operational magnets, have an $E_{u .1} \quad 0.35 \mathrm{~J} / \mathrm{m}$ and $0.1 \mathrm{~J} / \mathrm{m}$ respectively.

\section{CRYOGENICS}

The coil is indirectly cooled at an operating temperature of $4.5 \mathrm{~K}$ using the thermo-siphon technique( Fig.4 shows the schematic of the cryogenic circuit). The liquid helium is circulated in channels welded to the support cylinder. The piping was designed for a steady-state cooling flow of $30 \mathrm{~g} / \mathrm{sec}$.

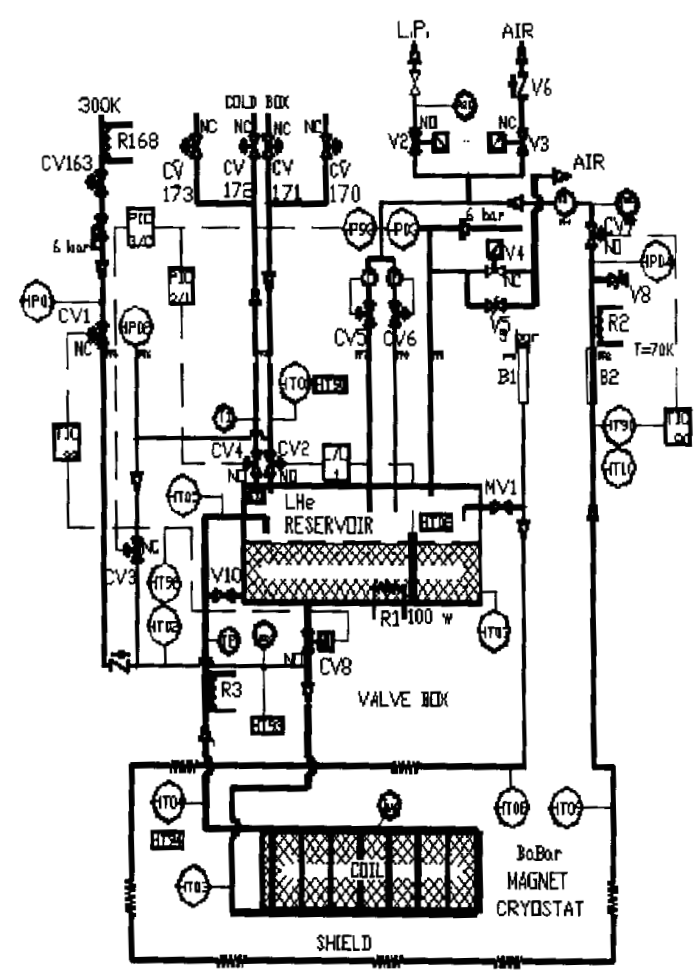

Figure 4. Cryogenic scheme 
Cooldown and cryogenic supply to the coil and $40 \mathrm{~K}$ radiation shields is accomplished by a modified Linde TCF-200 liquefier/refrigerator. Liquid helium and cold gas from the liquefier/refrigerator and its $4000 \mathrm{l}$ storage dewar is supplied to the coil and shields via $60 \mathrm{~m}$ long, coaxial, return gas screened, flexible transfer line. It is possible to cool down the coil by a mixture of warm and cold $\mathrm{He}$ gas or by supplying colder and colder gas through the refrigerator. The shields are cooled by part of gas coming back from coil. The actual cool-down at SLAC took about a week as shown in fig.5. The heat load measurement at $4.5 \mathrm{~K}$ was performed by closing the input valve to the $4000 \mathrm{l}$ control dewar and by measuring the $\mathrm{LHe}$ consumption in that dewar. This test gives pessimistic information because the transfer line losses are included too.

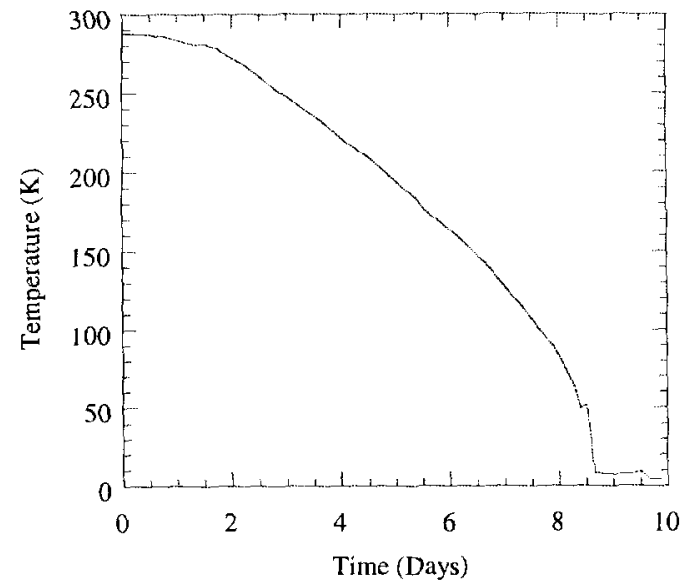

Figure5. Coil average temperature during cool-down

A total loss of $35(+2,-3) \quad W$ was measured., with no power in the coil. During the test, the mass flow rate in each lead was $70 \mathrm{NLP} / \mathrm{m}$, this means a load of $4 \mathrm{~W}$ per lead. When coil was powered at $1.58 \mathrm{~T}$ the mass flow rate per lead (at a voltage across each led of $40 \mathrm{mV}$ ) was $90 \mathrm{NLP} / \mathrm{m}$ corresponding to a heat load of $5 \mathrm{~W}$ per lead. Mixing these data and considering that $3 \mathrm{~W}$ loss are due to the transfer line we concluded that heat load was between $19 \mathrm{~W}$ and $24 \mathrm{~W}+14 \mathrm{l} / \mathrm{h}$. This very low value of the loss is partially due to the shield temperature ( $45 \mathrm{~K}$ ). The shields were cooled by cool helium gas coming from the $\mathrm{LHe}$ reservoir in the Valve Box.

The shield temperatures ranges between 37 and $49 \mathrm{~K}$ with a mass flow rate of $0.35 \mathrm{~g} / \mathrm{s}$. The total loads at the shield is $87 \mathrm{~W}$.

\section{OPERATION}

The coil current was incrementally increased to $4605 \mathrm{~A}$. The central field measured with an Hall probe was $1.503 \mathrm{~T}$. The operating current for $1.50 \mathrm{~T}$ was then determined to be $4596 \mathrm{~A}$ and the design current ( 1.05 times the nominal current) was determined to be 4825 A. On charging the coil at $1.00 \mathrm{~A} / \mathrm{s}$ the inductive voltage across the coil was $2.573 \mathrm{~V}$. The measured inductance is $2.573 \mathrm{H}$, which is in good agreement with computation (2.56 $\mathrm{H})$. The final step in the commissioning process was to charge the solenoid to the design current of $4826 \mathrm{~A}$. The measured field at the design current was $1.58 \mathrm{~T}$.

The coil is protected with the usual method of a resistor in parallel. If a quench is detected $(50 \mathrm{mV}$ unbalance signal between the two voltages in two layers), a breaker opens, closing the current in coil and dump resistor.

The peak voltage at the coil ends can be as high as $340 \mathrm{~V}$. Considering that the center tap of the dump resistor was shorted to ground, the maximum voltage to ground is $170 \mathrm{~V}$. Fig. 6 shows current during a fast dump from $4600 \mathrm{~A}$. The fast discharge from the nominal current causes a quench due the heating of the supporting cylinder (Quench Back).

The coil temperature increases to $37 \mathrm{~K}$ uniformly. In these conditions about 5 hours are needed to cool-down the coil again, fill the reservoir and be ready for re-charging. 


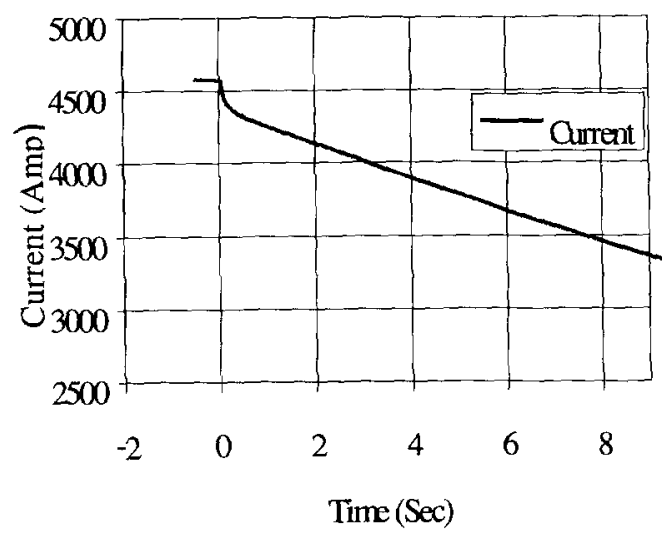

Figure 6. Coil current during fast dis-charge. Time $\mathrm{t}=0$ is the breaker opening

\section{MAGNETIC FORCES}

The coil is placed inside a non-symmetric flux return yoke. This gives rise to axial offset forces. The net axial force is the difference of two large compressive forces of approximately $380 \mathrm{MT}$ on the forward and backward ends of the coil. It is very sensitive to the axial location of the coil within the barrel; the gradient is approximately $1.5 \mathrm{MT} / \mathrm{mm}$ of axial displacement.

In order to have an offset force in one direction only (no inversion during the ramp up), the coil was positioned with $30 \mathrm{~mm}$ axial displacement in the forward direction. Fig. 7 shows the measured axial offset force as resulted from the strains in the three Inconel 718 tie rods placed at the backward side. These tie rods were designed to hold forces as high as 25 ton with a safety factor of 4. Forces on single tie rod and total force (sum of the three) are shown. The total force is forward directed and has a maximum of 8 ton at $3800 \mathrm{~A}$. The three tie rods at the opposite side (forward) are not strained.

The force behavior vs. current is in agreement with a axial displacement of 33 $\mathrm{mm}$ in forward direction of the coil with respect to the iron (as resulted from ANSYS and MERMAID 2D computation [4]). The average strain in the three tie rods is 500 $\mu \mathrm{m}$ corresponding to $0.3 \mathrm{~mm}$ displacement.

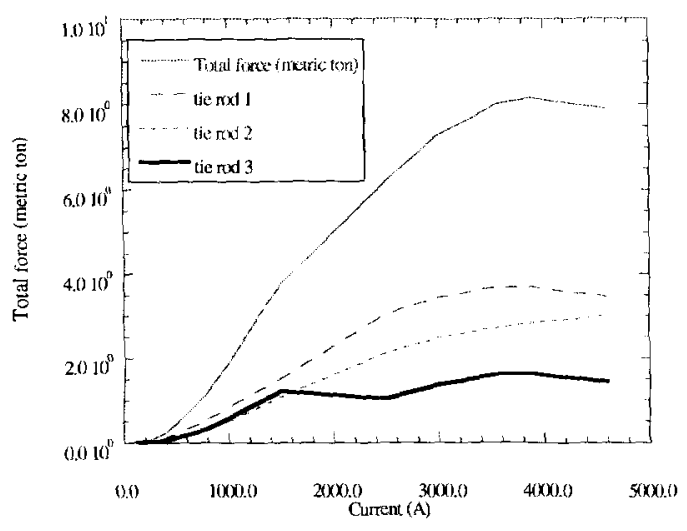

Figure 7. Axial forces in the solenoid backward end tie rods.

\section{SUMMARY}

The superconducting solenoid was successfully commissioned in March 1998, and following a detailed field map the solenoid was then warmed up for final assembly of the BABAR detector. In November 1998 the coil was put again in operation for cosmic ray run.

\section{REFERENCES}

1 BABAR collaboration "Technical design report," SLAC note R-95-457, 1995

2 H.Desportes et al, 'Construction and Test of the CELLO 'Thin-Wall Solenoid' Ad. Cryogenic Eng. 25, p. 175, 1980

3 P.Fabbricatore, R.Musenich, and R.Parodi, "Inductive method for critical measurement of superconducting cables for high energy physics applications," NIM, vol. A302, 1991, pp. 27-35

4 Program MERMAID was written at the Budker Institute of Physies, Novosibirsk, 1994. 